\title{
Molecular Biomimetics vs Materials Science
}

\author{
Mehmet Sarikaya ${ }^{1,2}$
}

1. GEMSEC, Genetically Engineered Materials Science and Engineering

2. Department of Materials Science and Engineering, Chemical Engineering and Oral Health Science, University of Washington, Seattle, WA 98195, USA

Materials are structure sensitive. To design functions of the materials, such as metals, their alloys, ceramics, composites and semiconductors, the structures are controlled using a variety of processing and heat-treatment methods in materials science and engineering, often called "heat-and-beat" [1]. A wide variety of structures in biology, however, are multifunctional with highly intricate internal structures, all formed at room temperature, in aqueous environment under atmospheric pressures, involving virtually no heat [2]. The question therefore, is how are the structures of biological hard tissues are formed, what controls their formation and of these highly multifunctional and often hierarchical materials? For example, in mother-of-pearl of red abalone, the structure is laminated and consist of layered aragonite hard $0.5 \mu \mathrm{m}$ thick crystallites separated by $10 \mathrm{~nm}$-thick thin film soft organic matter, forming one of the toughest and strongest materials ever produced by biology [Fig. 1). In duel-phase medium-carbon steels, the microstructure also consists of two phases, $0.5 \mu \mathrm{m}$ thick martensite, the hard phase, and $10 \mathrm{~nm}$-thick retained austenite, resulting in a kinetically formed material one of the toughest and hardest materials ever produced by metallurgists.

If not heat, what is key the factor that controls synthesis and structure formation in biological hard tissues? In addition to the mineral phase, the only other common component of hard tissues, such as bacterial magnetite, tooth enamel, and sponge specular optical fibers, are proteins (Fig. 1). Proteins, through their unique and specific interactions with other macromolecules and inorganics, control structures and functions of all biological hard and soft tissues in organisms. The specialized proteins associated with each hard tissue have highly specific amino acid sequences, which by transporting ions, nucleating the inorganic phase, also control their growth and morphogenesis; proteins, therefore, are the work horses in biology [2]. For materials science, the use of proteins in materials formation is highly attractive although they are usually very long, complex, and their functions are difficult to decipher.

Following Mother Nature's ways, we have adapted genetic engineering approaches, in particular combinatorial mutagenesis, in selecting specialized peptide sequences with affinity to inorganic solids, Despite their short AA sequences, usually 7-14, these genetically engineered peptides for inorganic (GEPI) have functions similar to proteins, e.g., molecular linkers, erectors, and assembler as well as tiny enzymes, used as molecular building blocks in nanotechnology and molecular medicine. Molecular biomimetics is an emerging field in which hybrid technologies are developed by using the tools of molecular biology and materials sciences. Following the footsteps of biology, GEPIs can now be used for mineralization of plasmonic metal nanoparticles, dielectric photonic crystals, and biomineralization of teeth and bone-like structures (Fig. 2). Based on the three fundamental principles of molecular recognition, self-assembly and DNA manipulation, the GEPIs are the key enablers in controlling the soft bio/nano interfaces and, hence, the surface phenomena on atomically-flat solids enabling biomolecular nanostructures on single-atomic layer materials linking biology and solid-state devices towards creating novel technologies, e.g., highly sensitive genetically-designed biosensors, enzymatically controlled biofuel cells, and interface engineered field effect transistors (Fig. 3). 
The work has been supported by NSF-MRSEC, ARO-DURINT, NIH-NCI, and LSDF Funds.

\section{References}

[1] W. D. Callister \& D. G. Rethwisch, Materials Science \& Engineering, Wiley, NY, 2010.

[2] D. L. Nelson \& M. M. Cox, Lehninger Principles of Biochemistry, Freeman \& Co., NY, 2008.

[3] M. Sarikaya et al., "Molecular Biomimetics” Nature Materials, 2(9) 577-585 (2003).

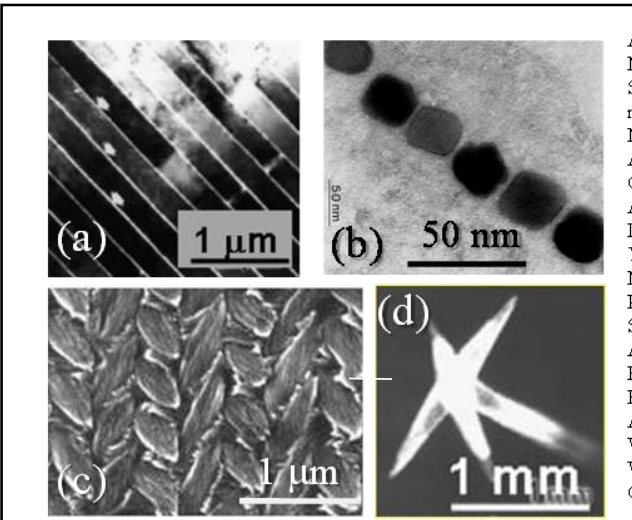

Aragonite protein AP7 precursor (Haliotis rufescens (California red ab alone) MTYMCSIICLVLICARGAEADDNGNYGNGMASVRTQGNTYDDLA SLISYLTRHSFRRPFHECALCYSITDPGERQRCDMYCSYTN mms6 - Bacterial magnetic particle specific iron-binding protein MGEMEREGAAAKAGAAKTGAAKT GTVAKTGIAAKTGVATAVAAPA APANVAAAQGAGTKVALGAGKAAAGAKVVGGTTWTGKGLGLGLGL GLGAWGPII GVVGAGAVYAYMKSRDESAQSDEEVELRDALA Amelogenin - AMEX: HUMAN Amelogenin,- $\mathrm{H}$ sapiens MGTWI

FACLLGAAFAMPLPPHPGHPGYINFSYEVLTPLKWYOSRPPYPSYG YEPMGGWLHHOIPVLSOOHPPTHTLOPHHHIPVVPAOQPVIPOOPM YEPMGGWLHHQIPVLSQQHPPTHTLQPHHHIPVVPAQQPVIPQQPM
MPVPGQHSMTPIQHHQPNLPPPAQQPYQPQPVQPQPHQPMQPQPPVH MPVPGQHSMTPIQHHQPNLPPPAQQPYQPQPVQPQPHQPMQPQPP
PMQPLPPQPPLPPMFPMQPLPPMLPDLTLEAWPSTDKTKREEVD Silic atein-alpha - Hymeniaci don perleve (Marine sponge) MXLSVTLLSLLA AAFAVQPKFEFVEEWQMWKSRHSKIYESKLVELERHLTWVSINKKYI EOHNANSHIFGFTLAMNKFGDMSELEWANFLSYBSD GKSK GNYTKT FOPDPRVHD YPEADWR TK GAVTAVRDOGDCGASYAFS AMGAIEG AYAL AHNGNOESFSEONIIDCSPYGNYGCHGGNMYDAFI YUIANTG

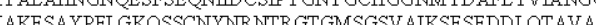
AKESAYPFLGKQSSCNYNRNTRGTGMSGSVAIKSESEDDLQTAVA VGPVAVAID GANNAFRFYYSGVYDSSRCSSTSLNHAMVVTGYGTY
GKKYWLAKNSWSTNWGQSGYVMMARGK YNQCGLATDASYPTL

Figure 1. Biological hard tissues: (a) Aragonite in mother-of-pearl of abalone shell, (b) Bacterial magnetite nanoparticles,

Hydroxyapatite in enamel of mammalian tooth, and (d) Siliceous light gathering lens of sponge spicules. The amino acid sequences are from the proteins isolated hard tissues, respectively.

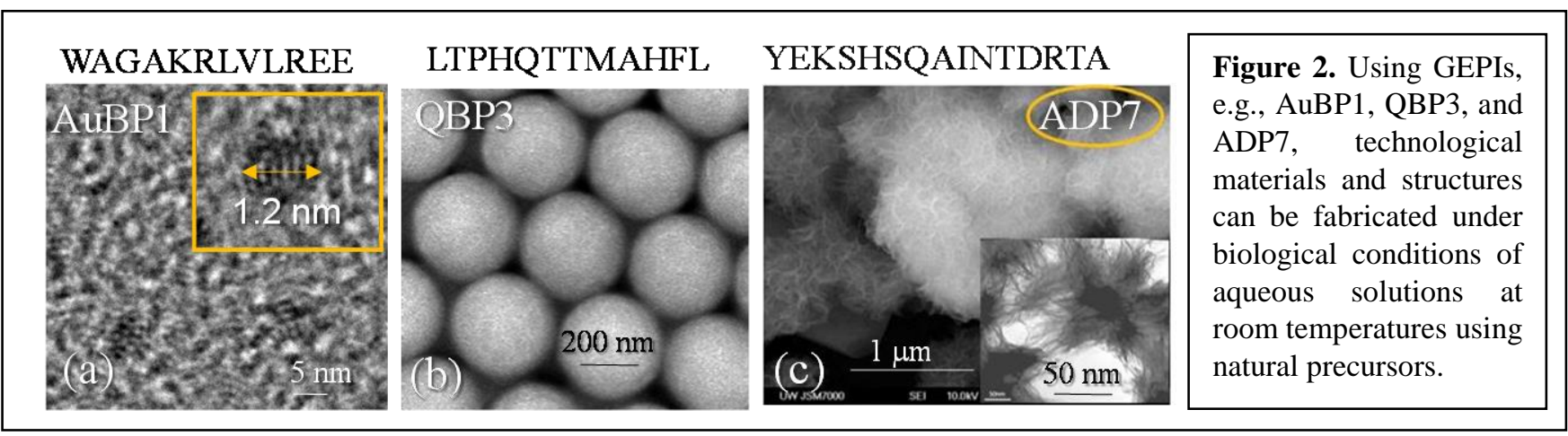

(a)

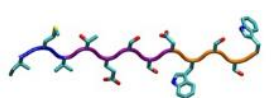

GrBP1: IMVTESSDYSSY
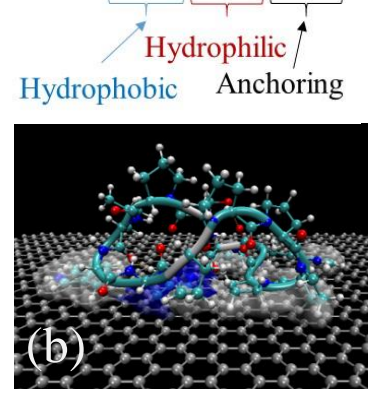
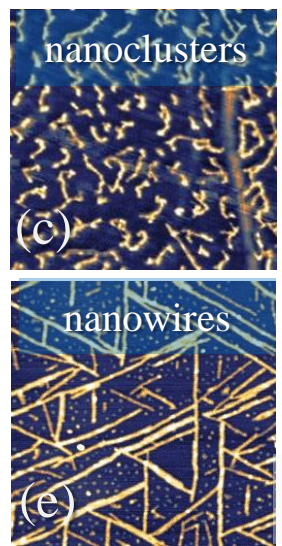

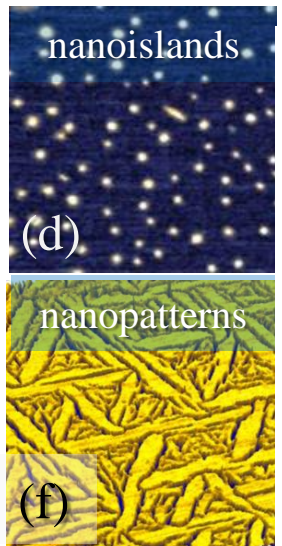

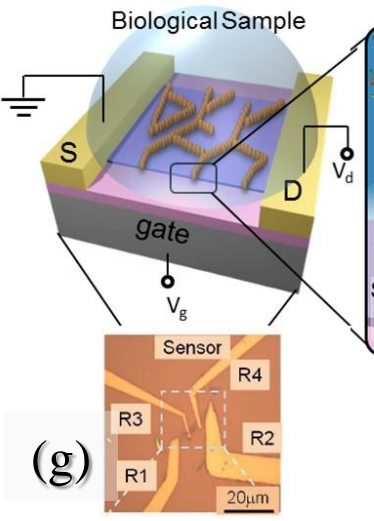

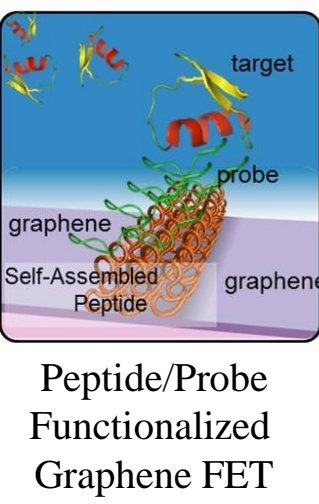

Figure 3. (a) Graphite binding peptide, GrBP5, (a) Binding to graphene, forming (c) Clusters, (d) Nanoislands, (e) Nanowires, and (f) Ordered patterns, all used for self-assembled nanobiosensors. 